\title{
Backpack Weight and Postural Angles in Preadolescent Children
}

\author{
S Milanese ANd K Grimmer-Somers* \\ Lecturer in Physiotherapy, and * Director, International Centre for Allied Health Evidence (ICAHE); Division of Health Sciences, \\ School of Health Sciences, University of South Australia, Adelaide, SA Australia 5000. Steve.Milanese@unisa.edu.au
}

I $t$ has been suggested that exposure to heavy school backpacks is a relatively recent phenomenon. Factors such as reduced use of student lockers secondary to security concerns, an increased use of laptop computers, and increased carrying of non-educational loads such as musical instruments and sports equipment have potentially increased student exposure to heavy load carriage. It is therefore pleasing to see research, as presented by Ramprasad and colleagues(1), continuing to raise awareness of this problem.

Laboratory studies, such as this, facilitate our understanding of the effect that the carriage of school backpacks has on the posture of students. Application of a load to the individual, via a backpack, results in increased forward lean of the trunk and neck to help overcome the effect on the body's centre of gravity. This finding supports earlier work by Chansirinukor, et al.(2).

As noted by the authors of this paper, it has been widely recommended that the maximal safe limit for percentage body weight $(\% \mathrm{BW})$ carried in a backpack was $10 \% \mathrm{BW}$, although to date this value has not been substantiated scientifically. Of particular interest in this study is that a postural effect can be seen from the application of a backpack load as low as $5 \% \mathrm{BW}$. Backpack loads of $5 \% \mathrm{BW}$ have been shown to result in changes in pulmonary function amongst Chinese schoolgirls(3).

Whilst this study adds to the growing body of research quantifying the biomechanical effect of a backpack load, the effect of these changes in posture, gait and the physiological costs associated with load carriage on the risk of musculoskeletal injury remains unclear. Some authors have even cautioned against the use of $\% \mathrm{BW}$ limits(4), as it fails to take into account a range of personal factors, such as the adolescent's physical reactions to heavy loads, muscle strength, height, age and psychosocial factors. This is particularly important during adolescence as the wide variation in timing and tempo of normal pubertal development means that within a 'normal' population of subjects between 10 and 19 years of age, individuals will be at different stages of their psychophysical development. To describe the individuals in this study as 'preadolescent', without a measure of their pubertal development may be oversimplifying this potentially confounding variable.

A number of studies have found no relationship between load carried (as \%BW) and symptoms, but rather with the perception of heaviness or fatigue(5). This supports the notion that the relationship between load carriage and musculoskeletal symptoms is far more complex than it first appears.

Steele, et al.(6), in a systematic review of the literature related to load carriage and the postural effects, concluded that due to the lack of rigorous research in this area, it was impossible to construct evidence-based recommendations on optimal load carriage for adolescents. The type of research presented in this paper, is the first step and would hopefully stimulate more work in this area.

Funding: None.

Competing interests: None stated. 


\section{REFERENCES}

1. Ramprasad M, Alias J, Raghuveer AK. Effect of backpack weight on postural angles in preadolescent children. Indian Pediatr 2010; 47: 575-580.

2. Chansirinukor W, Wilson D, Grimmer K, Dansie B. Effects of backpacks on students: measurement of cervical and shoulder posture. Australian $\mathrm{J}$ Physiother 2001; 47: 110-116.

3. Chow DHK, Kwok MLY, Au-Yang ACK, Holmes $\mathrm{AD}$, Cheng JCY, Yao FYD, et al. The effect of backpack load on the gait of normal adolescent girls. Ergonomics 2005; 48: 642-656.

4. Goodgold S, Corcoran M, Gamache D, Gillis J, Guerin J, Coyle JQ. Backpack use in children. Pediatric Physical Therap 2002; 14: 122-131.

5. Puckree T, Silal SP, Lin J. School bag carriage and pain in schoolchildren. Disability Rehab 2004; 26: 54-59.

6. Steele E, Bialocerkowski A, Grimmer K. The postural effects of load carriage on young people A systematic review. BMC Musculoskel Disorders 2003; 4: 12 . 